\title{
Anthropometric evaluation and micronutrients intake in patients submitted to laparoscopic Roux-en-Y gastric bypass with a postoperative period of $\geq 1$ year
}

- Tânia Mercachita,

- Zélia Santos,

- Jorge Limão,

- Elisabete Carolino,

- Lino Mendes

\section{Abstract}

\section{Background}

Bariatric surgery is indicated as the most effective treatment for morbid obesity; the Roux-en- $Y$ gastric bypass (RYGB) is considered the procedure of choice. However, nutritional deficiency may occur in the postoperative period as a result of reduced gastric capacity and change in nutrients absorption in the gastrointestinal tract. The prescription of vitamin and mineral supplementation is a common practice after RYGB; however, it may not be sufficient to prevent micronutrient deficiencies. The aim of this study was to quantify the micronutrient intake in patients undergoing RYGB and verify if the intake of supplementation would be enough to prevent nutritional deficiencies.

\section{Methods}

The study was conducted on 60 patients submitted to RYGB. Anthropometric, analytical, and nutritional intake data were assessed preoperatively and 1 and 2 years postoperatively. The dietary intake was assessed using 24-h food recall; the values of micronutrients evaluated (vitamin B12, folic acid, iron, and calcium) were compared to the dietary reference intakes (DRI).

\section{Results}

There were significant differences $(p<0.05)$ between excess weight loss at the first and second year $(69.9 \pm 15.3$ vs $9.6 \pm 62.9 \%)$. In the first and second year after surgery, 93.3 and $94.1 \%$ of the patients, respectively, took the supplements as prescribed. 
Micronutrient deficiencies were detected in the three evaluation periods. At the first year, there was a significant reduction $(p<0.05)$ of B12, folic acid, and iron intake.

\section{Conclusions}

Despite taking vitamin and mineral supplementation, micronutrient deficiencies are common after RYGB. In the second year after surgery, micronutrient intake remains below the DRI.

Journal

\section{Obesity Surgery}

DOI

10.1007/s11695-013-1057-1

Print ISSN

0960-8923

Online ISSN

1708-0428

Publisher

Springer US

Additional Links

- Register for Journal Updates

- Editorial Board

- About This Journal

- Manuscript Submission

Topics

- $\underline{\text { Surgery }}$

Keywords

- Bariatric surgery

- Roux-en-Y gastric bypass

- Nutritional deficiencies

- Dietary intake

- Micronutrients

Industry Sectors

- Biotechnology

- Consumer Packaged Goods

- Health \& Hospitals

- Pharma

Authors 
- Tânia Mercachita $\square^{(1)}$

- Zélia Santos ${ }^{(2)}$

- Jorge Limão $^{(3)}$

- Elisabete Carolino ${ }^{(4)}$

- Lino Mendes $^{(4)}$

Author Affiliations

- 1. Rua Alfredo Rebelo, Casais de Baixo, 2050-360 Azambuja, Lisbon, Portugal

- 2. Hospital Egas Moniz, Lisbon, Portugal

- 3. BaroClinic, Lisbon, Portugal

- 4. Escola Superior de Tecnologia da Saúde de Lisboa, Lisbon, Portugal 